Correction

\title{
Correction: miR29a and miR378b Influence CpG-Stimulated Dendritic Cells and Regulate cGAS/STING Pathway
}

\author{
Abid Ullah Shah ${ }^{1}$, Yanan Cao ${ }^{1}$, Naila Siddique ${ }^{2}$, Jian Lin ${ }^{1,3, * \mathbb{C}}$ and Qian Yang ${ }^{1, *}$ \\ 1 College of Veterinary medicine, Nanjing Agricultural University, Wei gang 1, Nanjing 210095, China; \\ abidullahshah@yahoo.com (A.U.S.); yncao1994@163.com (Y.C.) \\ 2 National Reference Laboratory for Poultry Diseases, Animal Sciences Institute, National Agricultural \\ Research Center, Islamabad 44000, Pakistan; naila.nrlpd@gmail.com \\ 3 College of Life Sciences, Nanjing Agricultural University, Wei gang 1, Nanjing 210095, China \\ * $\quad$ Correspondence: linjian@njau.edu.cn (J.L.); zxbyq@njau.edu.cn (Q.Y.)
}

Received: 12 September 2019; Accepted: 11 November 2019; Published: 16 June 2020

The authors wish to make the following corrections to this paper [1]:

The authors would like to apologize for any inconvenience caused to the readers by these changes.

The authors wish to make the following correction to this paper [1]: Due to our mishandling we inserted a wrong image of GAPDH in Figure 6B; therefore, we want to replace the GAPDH image of Figure 6B with the old one:

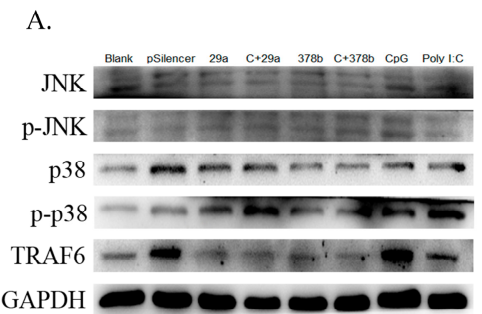

C.
E.<smiles>[131In]</smiles>

B.

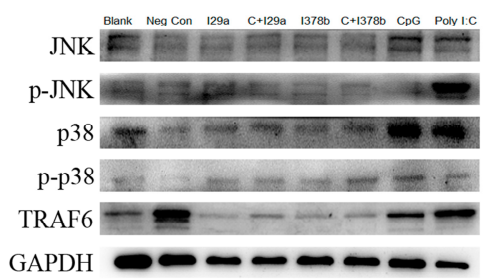

G.

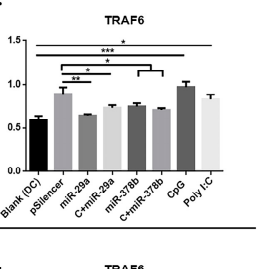

H.
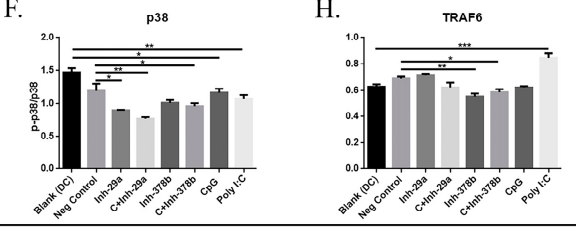

with 
A.

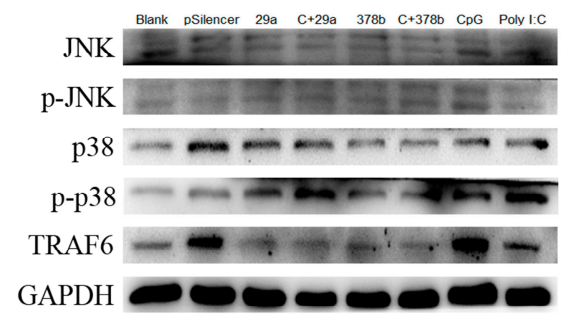

C.

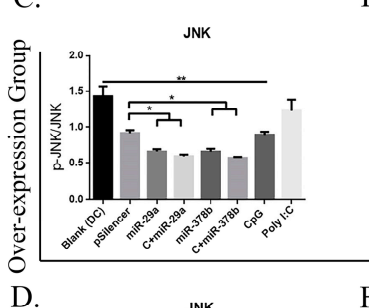

E.

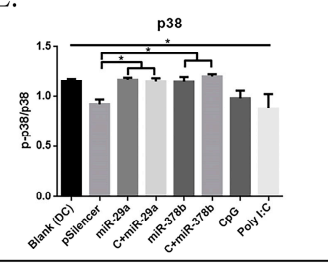

B.

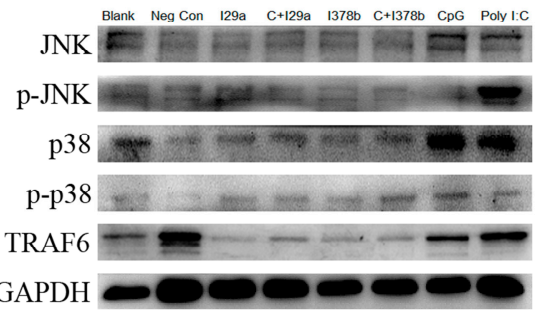

G.

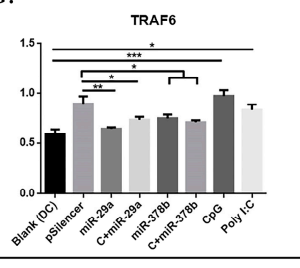

H.

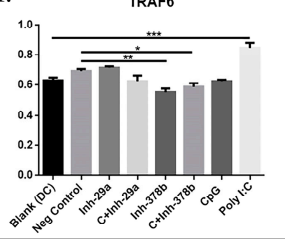

Conflicts of Interest: The authors declare that they have no conflict of interest.

\section{Reference}

1. Shah, A.U.; Cao, Y.; Siddique, N.; Lin, J.; Yang, Q. miR29a and miR378b Influence CpG-Stimulated Dendritic Cells and Regulate cGAS/STING Pathway. Vaccines 2019, 7, 197. [CrossRef] [PubMed]

(C) 2020 by the authors. Licensee MDPI, Basel, Switzerland. This article is an open access article distributed under the terms and conditions of the Creative Commons Attribution (CC BY) license (http://creativecommons.org/licenses/by/4.0/). 